\title{
Correction to: Achieving Glycaemic Control with Concentrated Insulin in Patients with Type 2 Diabetes
}

\author{
Sudesna Chatterjee ${ }^{1,2}\left(\mathbb{D} \cdot\right.$ Kamlesh Khunti $^{3} \cdot$ Melanie J. Davies $^{3}$
}

Published online: 31 January 2019

C) Springer Nature Switzerland AG 2019

\section{Correction to: Drugs}

https://doi.org/10.1007/s40265-018-1048-6

Page 7, Sect. 4.1, third paragraph, which previously read:

In a small Japanese trial of 24 participants with T2DM randomised to either glargine U300 or degludec U100 where the primary endpoints were hypoglycaemia and mean percentage of time spent in target glucose range as assessed by flash glucose monitoring over 14 days, there was no significant difference between the insulins for glycaemic efficacy, although insulin degludec was associated with significantly lower rates of nocturnal hypoglycaemia $(p=0.007)$ [36]. The same researchers found similar results in another 30 patients with T2DM when these insulins were compared for glycaemic efficacy and hypoglycaemia using continuous glucose monitoring over 5 days [37].

Should read:

In a small Japanese trial of 24 participants with T2DM randomised to either glargine U300 or degludec U100 where the primary endpoints were hypoglycaemia and mean percentage of time spent in target glucose range as assessed by flash glucose monitoring over 14 days, there was no significant difference between the insulins for glycaemic efficacy, although insulin glargine U300 was associated

The original article can be found online at https://doi.org/10.1007/ s40265-018-1048-6.

Sudesna Chatterjee

Sudesna.chatterjee@abbott.com

1 University Hospitals of Leicester NHS Trust, Senior Clinical Researcher, University of Leicester, Leicester, UK

2 Present Address: Abbott Diabetes Care, Abbott Laboratories, Maidenhead, UK

3 Diabetes Research Centre, University of Leicester, Leicester, UK with significantly lower rates of nocturnal hypoglycaemia $(p=0.007)$ [36]. The same researchers found similar results in another 30 patients with T2DM when these insulins were compared for glycaemic efficacy and hypoglycaemia using continuous glucose monitoring over 5 days [37].

The original article has been corrected. 